\title{
NARRATIVIZAÇÃO E SUBVERSÃO SEXUAL: CONSIDERAÇÕES EM TORNO DE PUIG, ABREU E BAYLY
}

Anselmo Peres Alôs

Recebido 17, set. 2009 / Aprovado 29, abr. 2010

\section{Resumo:}

Este trabalho tem por objetivo a realização de uma análise contrastiva de três romances representativos da problematização da identidade homossexual masculina no continente latino-americano: El beso de la mujer araña (Argentina, 1976), de Manuel Puig; Onde andará Dulce Veiga? (Brasil, 1990), de Caio Fernando Abreu e No se lo digas a nadie (Peru, 1994), de Jaime Bayly. A articulação de uma epistemologia queer permite pensar a textualidade como o lugar de encenação de uma ficção política que questiona os regimes heteronomativos do sexo e do gênero, e propõe uma estratégia de resistência baseada tanto nos corpose nos prazeres quanto nas políticas de representação e reinvenção das masculinidades e das feminilidades. Tomando os pressupostos feministas, os estudos narratológicos e a teoria/epistemologia queer como sustentação teórica, realiza-se uma leitura crítica desses romances, os quais questionam o regime heteronormativo e investem no potencial subversivo de um lugar de enunciação do discurso literário marcado pela diferença e pela resistência aos dispositivos heteronormativos de regulação das identidades sexuais. Neste sentido, a literatura reescreve tanto o corpo sexual, tido como o lugar da subjetividade individual, quanto o corpo social/ nacional, entendido como uma ficção reguladora das sociabilidades corporais e sexuais. Com vistas a uma poética queer, busca-se evidenciar as contradições e impasses que emergem nos romances, particularmente em relação a questões de raça, classe e gênero, bem como as potencialidades e os pontos problemáticos da poética queer como lugar de intervenção cultural.

Palavras-Chave: Narratologia. Literatura latino-americana. Poética queer. 
I got lots of problems

Female trouble

Maybe I'm twisted

Female trouble

They say I'm skank

But I don't care

Go ahead! Put me in your electric chair

I got lots of problems

Female trouble

Maybe I'm twisted

Female trouble

Hey! Spare me your morals

Look out for yourself

What pleases me is paradise

I got lots of problems

Female trouble

Maybe I'm twisted

Female trouble

Oink! Oink! Oink! Oink!

I'm berserk! I like It! Fine!

As long as I'm making headlines

Ah! Ah! Ah! Yeah!

(Versos de John Waters, cantados por Divine na abertura do filme Female Trouble)

A literatura, pensada como instituição, não apenas possibilita a representação dos sujeitos: ela funciona também como uma das relações sociais que os produz. É importante percebê-la não apenas como elaboração estética, mas como artefato cultural, como veículo de representações simbólicas e valores sociais. Muito mais do que a voz singular de um artista, o artefato literário é a expressão de uma determinada perspectiva, de um determinado conjunto de interesses (MCGEE, 1992).

As tensões geradas pelas premissas das teorizações gays, lésbicas e feministas são extremamente produtivas para o desenvolvimento de novas estratégias textuais e intertextuais, de forma a minar as bases dos estereótipos sexuais cristalizados na cultura (BUTLER, 1993). Gênero e sexualidade, embora categorias distintas, não devem ser completamente desarticulados, 
visto que se corre o risco do completo apagamento das relações de poder estabelecidas sob o signo da diferença de gênero. Se por um lado gays e lésbicas sofrem os efeitos do discurso heteronormativo, por outro a pertença ao gênero feminino transforma radicalmente a experiência das lésbicas, diferenciando assim a socialização e, consequentemente, a textualização dos significantes gay e lésbica na literatura (BUTLER, 1999, p. 11-20).

Questionar a autonomia do sujeito, instituindo-o como uma posicionalidade, ou ainda, como a construção de um interesse, abre espaço para um debate problematizador das identidades nacionais. Benedict Anderson, em Nação e Consciência Nacional (1989), define as nações como comunidades imaginadas, ou seja, não são elas apenas definidas pelos limites territoriais: elas são também imaginadas e narrativizadas, no sentido de constituir a idéia do pluribus unum, a pertença de todos os cidadãos sob a égide de uma identidade partilhada. A literatura, e em especial o gênero romanesco, tem um importante papel nos processos de "imaginação narrativa" das nacionalidades. Edward Said, por sua vez, afirma que este processo de narrativização - via de regra - institui a identidade nacional como una e monolítica, sem que se dê espaço para as diferenças de classe, de raça, de gênero e de orientação sexual, entre outras (SAID, 1995). Tais diferenças, existentes entre os diferentes sujeitos abrigados sob a égide de uma identidade nacional, quando transformadas em capital cultural através da representação literária, abrem fissuras no interior da comunidade imaginada, expondo o que Bhabha identifica como as fronteiras internas da nação (BHABHA, 1998). Em tempos de nascimento de um imaginário global, planetário, ou ainda, transnacional, cabe destacar que muitos são os desterrados, os exilados, os estrangeiros. Alguns fatos poderiam soar como curiosidade de almanaque, tais como a possibilidade de asilo político por discriminação sexual oferecidos por nações como a Alemanha, a Dinamarca, a Holanda, a Suécia e a Noruega (JOR-

1 Guiana e Uganda são dois dos países que condenam participantes de "atos homossexuais" à prisão perpétua. Entre aqueles que condenam homossexuais à pena de morte, estão Paquistão, Arábia Saudita, Emirados Árabes Unidos, Iêmen, Irã, Chechênia, Sudão, Afeganistão, Nigéria e Mauritânia. De acordo com levantamento da Anistia Internacional, aproximadamente 70 países possuem legislações nas quais a homossexualidade é considerada delito grave, com previsão de penas de cinco a dez anos de reclusão.
NAL DO NUANCES, 1998, p. 8), ao mesmo tempo em que outras nações condenam legalmente comportamentos homossexuais com a pena de morte ou a prisão perpétua. ${ }^{1}$ Todavia, ao se pensar na heterogeneidade de tratamentos dada aos homossexuais nos mais diversos contextos nacionais, cabe perguntar: qual o lugar reservado para os outsiders sexuais nesse imaginário planetário? De que maneira é representado, no texto literário, o confronto entre as pertenças nacionais e as pertenças sexuais?

Textos literários são artefatos culturais, tecnologias discursivas que produzem e disseminam crenças e valores no espaço social. Na medida em que subjetividades e corpos relegados à condição de abjetos usurpam o lugar de autoria, o lugar da produção de capital simbólico e produzem, através de personagens e narradores, percepções de mundo alternativas nas quais as possibilidades eróticas são exploradas, analisadas 
e redimensionadas, tais corpos interferem performaticamente no espaço social. Afinal, se tanto os atos quanto os atributos de gêneros são sempre performativos, "então não há identidade preexistente pela qual um ato ou atributo possa ser medido; não haveria atos de gênero verdadeiros ou falsos, reais ou distorcidos, e a postulação de uma identidade de gênero verdadeira se revelaria uma ficção reguladora" (BUTLER, 2003, p. 201). Se a enunciação literária contribuiu em larga escala para a produção performativa das identidades nacionais em variados contextos históricos e geográficos com sucesso (ALÓS, 2008; 2009), poderia a enunciação literária produzir performativamente novas possibilidades e estratégias políticas para se vivenciar o corpo, o gênero e a sexualidade?

Se a crítica literária é sempre judicativa, é mister delinear o locus que produz dados julgamentos, o campo epistemológico norteador daquilo que entendo como produção de conhecimento e os vetores ideológicos aos quais o crítico se alinha (EAGLETON, 1978, 1983). Parte-se aqui do pressuposto de que as concepções teóricas envolvidas na tarefa de crítica e interpretação revelam quais os compromissos intelectuais assumidos pelo pesquisador. E a partir deste lugar que se realiza uma aproximação intertextual entre os romances El beso de la mujer araña, do argentino Manuel Puig (1976), Onde andará Dulce Veiga?, do brasileiro Caio Fernando Abreu (1990) e No se lo digas a nadie, do peruano Jaime Bayly (1994).

Hugo Achugar, intelectual uruguaio, afirma categoricamente que "se não tenho a liberdade de escrever o que me dá vontade, não faz sentido escrever [...] Em algum lugar, preciso defender a escrita como um espaço de liberdade" (ACHUGAR, 2006, p. 22). Pensar a identidade de gênero como performativa permite pensar, ainda que metaforicamente, que performativizar um determinado gênero é escrever socialmente um determinado gênero. Obviamente, subverter o gênero através dessas paródicas performances do masculino e do feminino não soluciona completamente o problema. Pelo contrário, cria novos problemas a serem resolvidos, problemas que a drag queen Divine, na canção de abertura de um famoso filme de John Waters, ${ }^{2}$ chama, com

2 PROBLEMAS FEMININOS (Female Trouble). Direção e roteiro: John Waters. Estados Unidos, 1974, 35 mm. 97 min. A canção Female Trouble, cantada por Divine no início do filme, é, também, de autoria de John Waters.

3 Em inglês, female trouble é uma expressão popular, utilizada para se falar polidamente da menstruação. toda sua autoridade de travesti, de female trouble. No momento em que um homem homossexual traveste-se e afirma que tem "problemas femininos", tem-se o elemento cabal para afirmar que a subversão não solucionou o problema de gênero. Afinal, nada mais problemático do que um homem - ainda que travestido afirmar que tem "problemas femininos". ${ }^{3}$ Todavia, a subversão do gênero cria, junto com estes outros problemas, outras maneiras - disjuntivas, alternativas, performativas - de se lidar com os antigos. Novas maneiras para ler-se não apenas os "problemas de gênero" da ficção de Manuel Puig, Caio Fernando Abreu e Jaime Bayly, mas também - por que não? - novas maneiras 
para se interpretar a obra Masculino y Femenino, de Osvaldo Salerno, uma polêmica instalação projetada para ser exibida nas portas dos banheiros da V Bienal do MERCOSUL, ocorrida em Porto Alegre, em 2005 (Fig. 1). Ou ainda, novas maneiras para se compreender a identidade de gênero de performers como Divine, a diva drag avant la lettre de Baltimore (Fig. 2), e também de tantas outras drags anônimas em seu luxo, em seu deboche e em seu descaramento, que, de tão políticas e subversivas em suas performances, não raro são espancadas e assassinadas com requintes de crueldade. ${ }^{4}$

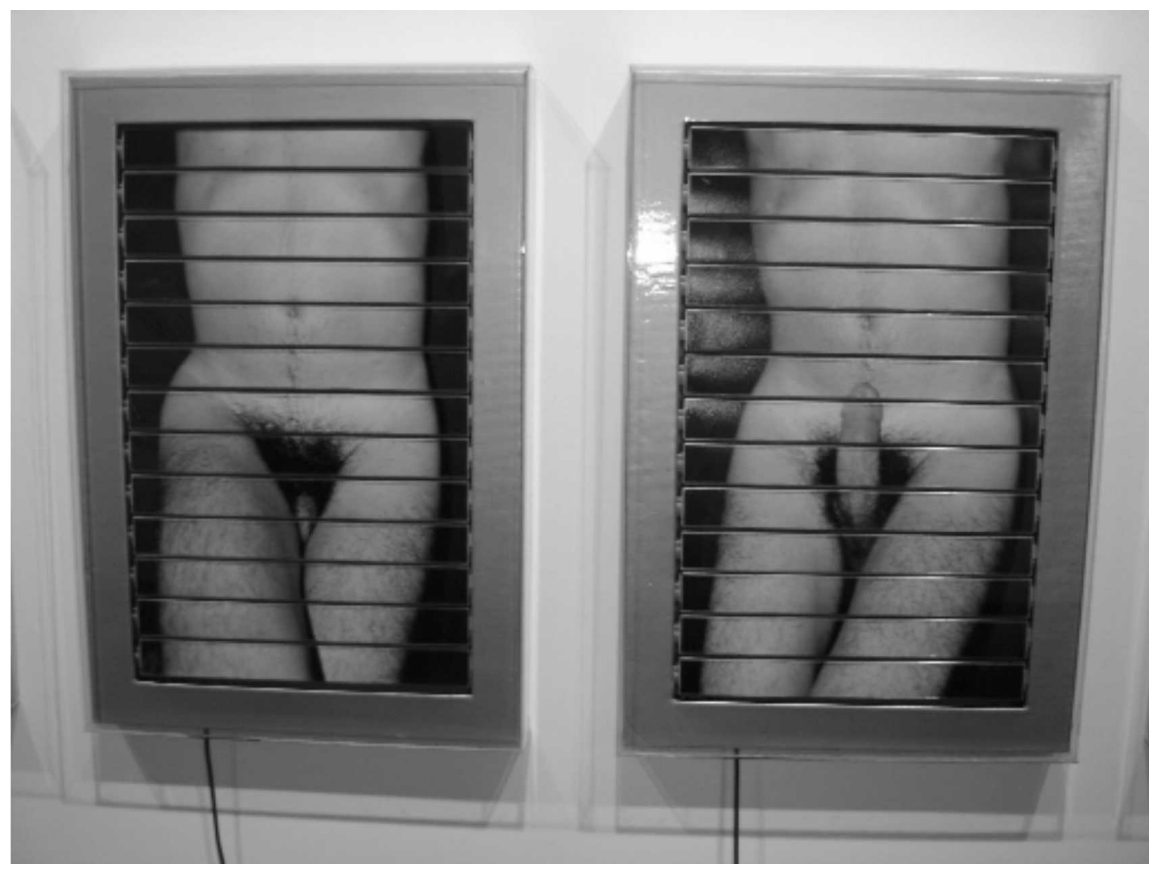

Figura 1: Masculino y Femenino

Osvaldo Salerno (artista plástico paraguaio)

Intervenção do artista em sanitários ecológicos (Usina do Gasômetro)

Quinta Bienal do Mercosul

Porto Alegre, 2005

Foto: Anselmo Peres Alós

Se tanto o social quanto o histórico intervêm nos processos de significação do texto literário, pode o literário intervir no histórico e no social? Se o social está implicado no literário, cabe perguntar: poderia então a linguagem poética servir como

4 De acordo com o Grupo Gay da Bahia, a cada dois dias um homossexual é assassinado no Brasil. Cabe destacar que as maiores vítimas da violência homofóbica são as travestis e as drag queens das classes sociais menos abastadas. lugar de investimento político de resistência, no qual a heteronormatividade pudesse ser contestada e subvertida? Através de quais estratégias tal investimento é tornado possível, e com que resultados? Poder-se-ia afirmar que os romances latino-americanos escritos por homens não-heterossexuais endossariam uma postura de afirmação identitária, a partir dos modelos propostos 
pelas subculturas gays "herdeiras" do levante do Stonewall Inn em 1969, ou ainda que, em sua escrita, autores como Manuel Puig, Caio Fernando Abreu e Jaime Bayly estariam preocupados em denunciar a violência homofóbica (seja ela física ou simbólica) no contexto das nações latino-americanas. Mesmo que tais assertivas estejam parcialmente corretas, elas se revelam um tanto reducionistas, frente às complexas problemáticas abordadas por estes três escritores.

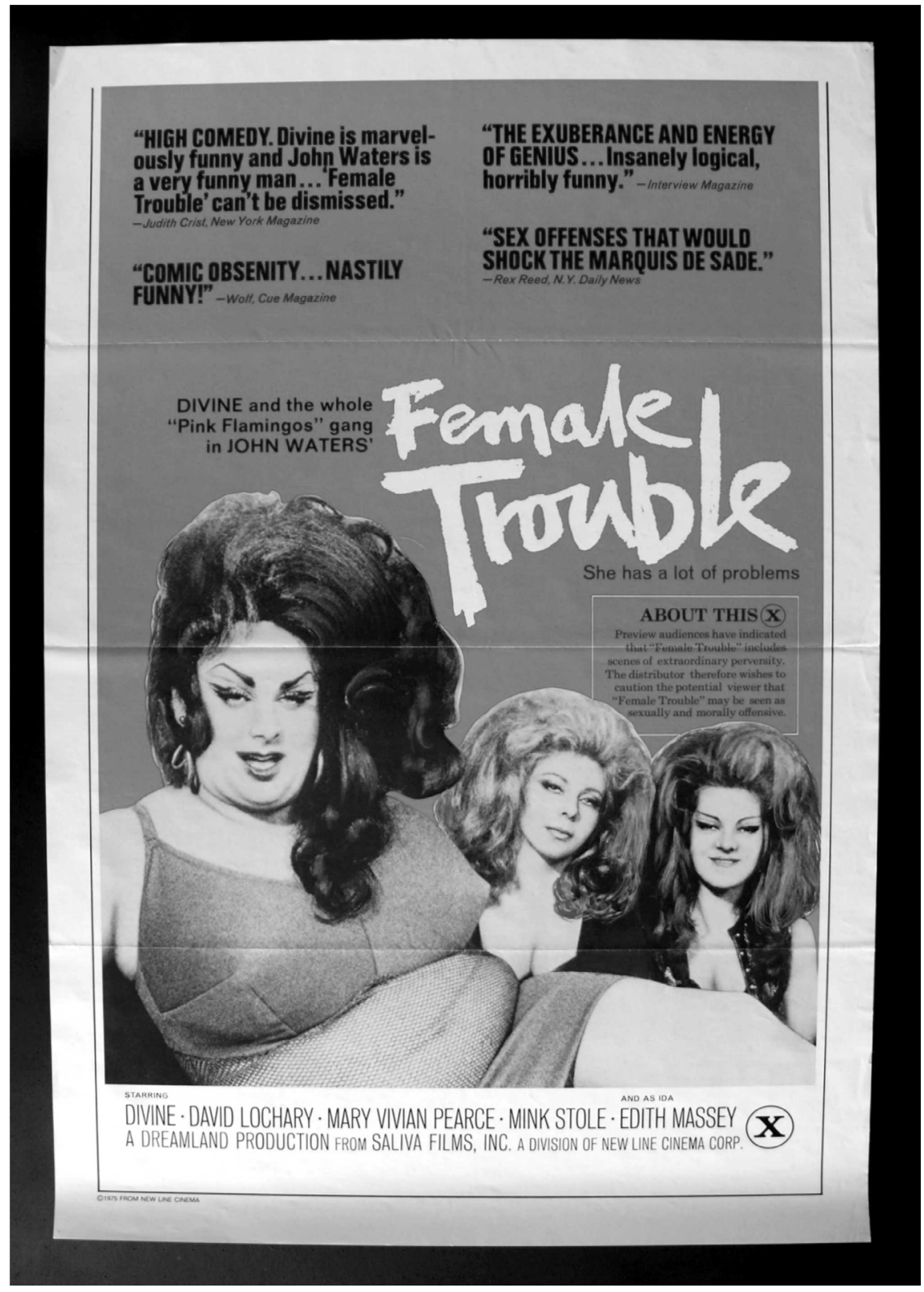

Figura 2: Cartaz de divulgação do filme Female Trouble, de John Waters (1974).

(Em primeiro plano, a drag queen Divine, a grande diva de John Waters). 
Se é possível afirmar que as apostas em estratégias de visibilidade estão presentes, em maior ou menor grau, nas três narrativas aqui analisadas, também o é afirmar que o investimento político em uma identidade gay centrada e monolítica é contestado, problematizado e mesmo refutado, particularmente no romance Onde andará Dulce Veiga?, de Caio Fernando Abreu. O narrador-protagonista do romance, que sequer é portador de um nome, apresenta uma postura de contestação e resistência - frente às tentativas sugeridas por outros personagens - de se enquadrar em um modelo prêt-à-porter de identidade homossexual masculina. Tal recusa a este modelo identitário hegemônico encontra ecos no gênero performativizado por Molina, personagem de El beso de la mujer araña. Molina consegue, ao mesmo tempo, questionar e subverter tanto o modelo heteronormativo de sexualidade quanto desafiar as estruturas sociais que julgam o sistema hierárquico de gênero como um binarismo restrito ao determinismo biológico. Uma vez que as categorias homem e mulher são desnaturalizadas e passam a ser vistas como dispositivos sociais, nada impediria, em princípio, que cada um desses personagens "assumisse" o gênero que mais lhe fosse conveniente. Assim sendo, por que as categorias homem e mulher continuam pautando, de maneira reiterada, os significados sociais que são atribuídos às performances identitárias de homens e mulheres homossexuais? Cabe aqui rememorar as reflexões realizadas por Monique Wittig (2002), ao afirmar que esta divisão binária somente faz sentido no interior de uma economia simbólica balizada nos imperativos de uma heterossexualidade compulsória, na qual o sistema sexo-gênero se resume a uma oposição hierárquica do gênero masculino ao gênero feminino. Atrelada à divisão binária dos gêneros, encontra-se também aquilo que Judith Butler (2003) chamou de matriz heterossexual, um esquema lógico que, a partir do binarismo fundacional do gênero e da lógica "biologizante" da reprodução sexual, legitima a heterossexualidade e torna a homossexualidade uma expressão libidinal abjeta.

A obra de Jaime Bayly permite que se esboce uma resposta para esta primeira questão. No se lo digas a nadie, romance de estréia de Bayly, é apresentado predominantemente por um focalizador cuja localização na hierarquia socioeconômica e racial é privilegiada. A estruturação do universo familiar patriarcal no qual Joaquín Camino está inserido indica que, conjuntamente com os preceitos modalizadores do discurso hegemônico da masculinidade, estão implicadas questões relativas ao prestígio social e à dominação racial. Abrir mão da identidade masculina hegemônica é abrir mão dos privilégios de ser homem no contexto de uma sociedade patriarcal. Fragilizar esta masculinidade, tal como é pressuposta, tem como consequência a abertura de fissuras para que outras vozes também subalternizadas - e não 
somente aquelas que o foram pela lógica heteronormativa questionem a primazia e a legitimidade da hegemonia branca, masculinista, economicamente mais favorecida e heterossexual. Admitir a existência de algo além, ocupando o entre-lugar formado pela intersecção do masculino e do feminino, abre espaço para que o edifício retórico construído com vistas a naturalizar a heterossexualidade como a única expressão sexual legítima comece a ser desmantelado através do discurso ficcional.

Ao questionar os binarismos em torno da construção social das categorias corpo, gênero e orientação sexual, o corpus analisado questiona o próprio lugar epistemológico a partir do qual se produz o conhecimento que legitima os arranjos binários da identidade de gênero e das práticas sexuais. $\mathrm{O}$ mais paradigmático enunciado a desestabilizar as categorias analíticas do pensamento hetero (WITTIG, 2002) é aquele inscrito em uma camiseta vestida pelo personagem Joaquín Camino, com a deliberada intenção de provocar a sua mãe: "I can't even think straight" (BAYLY, 2003, p. 326). Já o narrador-protagonista de Onde andará Dulce Veiga?, por sua vez, dispõe de ampla liberdade para transitar no "espaço aberto" da metrópole paulistana. Mesmo que este personagem questione a fixidez das identidades heteronormativas $e$ homonormativas, o desfecho do romance sinaliza uma mudança interior que liberta o personagem das amarras identitárias, mas não configura um embate direto com as formações ideológicas normativas no espaço social construído pelo narrador. Nesse sentido, a composição do texto literário na obra de Caio Fernando Abreu mobiliza um narrador interno (autodiegético) com alternâncias entre os regimes de focalização interna e externa. Tal artimanha narrativa permite a enunciação de um personagem conflitante e ambivalente, ao mesmo tempo em que evidencia um processo de constituição performativa da identidade sexual do mesmo. As aparentes contradições entre as ações do personagem e o discurso do narrador são resultantes da apresentação de um narrador com um duplo status: como narrador, o jornalista tem pleno conhecimento do desenrolar da história no tempo; como personagem, suas percepções são parciais. Apenas ao final do romance é que há uma co-incidência entre protagonista e narrador.

Joaquín Camino, por sua vez, deseja agir sobre estas formações ideológicas, em especial sobre os discursos do patriarcalismo branco e da moral religiosa, para poder enunciar, ainda que a contrapelo, a sua identidade sexual. Porém, ao mesmo tempo em que assume uma postura combativa com relação à heteronormatividade, o jovem mantém uma postura situacionista no que diz respeito aos privilégios que lhe são assegurados por seu pertencimento à elite branca de seu país. Joaquín opõe-se aos modelos patriarcais de família e de masculinidade que lhe são impostos desde a infância e, do mesmo modo, interroga critica- 
mente o conformismo de outros personagens, como Gonzalo e Alfonso, em especial a vivência de doble vidas, as quais permitem assegurar as benesses de se viver publicamente como um homem heterossexual, relegando a homossexualidade a uma questão de foro íntimo. Contudo, Joaquín termina optando pelo autoexílio em Miami, nos gay friendly Estados Unidos. Ao invés de se posicionar contra os privilégios de sua classe, o personagem utiliza-os para assegurar uma pacata vida em Miami, vivendo em um apartamento de propriedade da família.

É importante não confundir homossociabilidade com homossexualidade. Sendo a homossociabilidade entendida como a sociabilidade estabelecida entre homens, cabe ressaltar que ela é um importante aspecto na manutenção de uma cultura patriarcal. Ao pensar a homossociabilidade entre homens heterossexuais, fica evidente o papel que a homofobia e o sexismo têm na manutenção desse continuum de relações sociais. Isto é de extrema importância para que se possa compreender como e por que motivos o imperativo homossocial masculino por vezes reitera, reforça e legitima a opressão contra as mulheres:

I am not assuming or arguing either that patriarchal power is primarly or necessarily homosexual (as distinct from homosocial), or that male homosexual desire has a primary or necessary relationship to misogyny. Either of those arguments would be homophobic and, I believe, inaccurate. I will, however, be arguing that homophobia directed by men against men is misogynistic, and perhaps transhistorically so. (By "misogynistic" I mean not only that it is oppressive of the socalled feminine in men, but that it is oppressive of women) (SEDGWICK, 1990, p. 20).

Estes efeitos misóginos da homossociabilidade masculina são importantes para que se compreendam as aparentes contradições nos romances aqui analisados. Em No se lo digas a nadie, ainda que haja a emancipação do personagem Joaquín frente aos valores cultivados por sua família, as mulheres estão sempre subordinadas. Maricucha, a mãe de Joaquín, está ao mesmo tempo subordinada aos valores da direita católica (representados por sua afiliação ao Opus Dei) e à figura de Luis Felipe. Joaquín, por sua vez, é complacente com a violência homossocial em pelo menos dois momentos: quando presencia o espancamento de uma travesti no parque (BAYLY, 2003, p. 225-231), e quando tenta forçar uma garota a fazer sexo oral em troca de cocaína (BAYLY, 2003, p. 248-251).

O mesmo ocorre quando o protagonista de Onde andará Dulce Veiga? faz sexo com uma prostituta (ABREU, 1990, p. 110111) ou emite seu juízo de valor com respeito às integrantes do grupo Vaginas Dentatas, ao ouvir pela primeira vez o nome do grupo: "Sapatas, sexistas, adolescentes rebeldes sem causa nem conseqüência" (ABREU, 1990, p. 16). Aqui, mais uma vez, 
é a distinção entre narrador e focalizador que permite constatar uma possível ambivalência do texto, a qual apontaria para duas possíveis leituras. Sabendo que o narrador está enunciando o seu discurso do mesmo lugar que o protagonista, descobre-se, ao final do romance, que o narrador amava e estimava quase todos os outros personagens, fato que se evidencia com a "visão" que este tem em Estrela do Norte: "no centro da minha testa, havia um ponto como a lente na extremidade de um telescópio que eu apontava para as pessoas que eu amava, e que estavam distantes. [...] Voltei-as na direção de Pedro, mas estavam embaçadas" (ABREU, 1990, p. 211). Este "embaçamento", como oposição à "clareza" com que o narrador pode ver todos os outros personagens, instaura uma dúvida. Posto que a "lente" lhe permite "ver à distância" àqueles que ama, isto poderia ser lido como: a) uma certa "obscuridade" em relação aos sentimentos nutridos por Pedro (seu primeiro amante); ou b) assinalar a morte do amante em decorrência da infecção pelo vírus HIV. Uma vez que, ao final da história, o narrador explicita não haver dúvida alguma sobre os sentimentos que nutria por Pedro, confirma-se a segunda hipótese.

Quais seriam, pois, os ideologemas que sustentam a textualização de uma poética queer? Os ideologemas surgem de temas e estratégias discursivas recorrentes nos romances em questão, entendidos como eixos de análise. A partir da leitura dos romances de Manuel Puig, Caio Fernando Abreu e Jayme Bayly, é possível identificar a recorrência de três pontos fundamentais: a) o esforço de se construir um lugar de enunciação literária marcado pelo queer; b) as disjunções entre corpo, gênero e sexualidade; e c) a problematização da identidade e do pertencimento nacional a partir do desejo pelo reconhecimento. $\mathrm{Ou}$, de maneira simplificada, o ideologema da letra, o ideologema do corpo e o ideologema do desejo.

Sob o signo da letra, articula-se um ideologema no qual a escrita literária é problematizada a partir de um locus de enunciação consciente de suas implicações políticas mais amplas. Reivindica-se, através do alcance e da legitimidade do discurso literário, o exercício narrativo como um ato performativo, capaz de intervir no social através da projeção de novas configurações de identidade sexual e de gênero. Se para Fredric Jameson (1992, p. 15-103), a interpretação é um ato socialmente simbólico, para os narradores construídos por Puig, Abreu e Bayly a escritura também é um ato socialmente simbólico, com a capacidade de dialogar, desestruturar e subverter os saberes institucionalizados pelos discursos da biologia, da religião e da psicologia, bem como os saberes hegemônicos que circulam sob o rótulo de senso comum.

No romance de Puig, o investimento na escrita e em seu potencial disjuntivo com relação aos saberes hegemônicos é 
evidenciado pela dobra textual que divide El beso de la mujer araña em dois. Paralelamente à ação apresentada no enredo, que toma como base a temporalidade necessária para o estabelecimento dos diálogos entre Molina e Valentín, as notas de rodapé estabelecem uma dobra textual externa ao enredo (mas interna à narrativa, pelo viés da enunciação do discurso romanesco), na qual a legitimidade do discurso científico é subvertida e substituída pelo discurso "científico" de um personagem. Depois de uma extensa tarefa de revisão bibliográfica com relação ao tema da homossexualidade, o narrador externo (extradiegético), presente nas notas de rodapé, abre espaço para que o livro Sexualidad y revolución (título sintomático da "revolução" que o narrador almeja para a questão da homossexualidade) apresente uma possibilidade para que se compreenda a homossexualidade como um ato de insubordinação frente às hierarquias opressivas a delinear a "coerência" das identidades de sexo e de gênero. ${ }^{5}$

Em Onde andará Dulce Veiga?, a credibilidade da escritura como processo de constituição identitária é tão forte que o narrador-protagonista chega a cunhar uma peculiar ideia do que concebe por "deus" ou "divindade", quando afirma ter perdido "o vício paranóico de estar sendo sempre filmado ou avaliado por um deus de olhos multifacetados, como os das moscas, mas não o de estar sendo escrito" (ABREU, 1990, p. 13 - grifo meu). À afirmação final do narrador no romance de Abreu "e eu comecei a cantar" (ABREU, 1990, p. 213), pode ser atribuído o caráter metafórico de e eu comecei a escrever. Em última instância, de nada valeria a experiência vivida se a ela não fosse possível atribuir sentido através de um processo de narrativização, o qual a torna passível de ser compartilhada e lhe dá a permanência e a legitimidade da letra escrita, permitindo a instituição de novas possibilidades identitárias sob a forma de capital cultural. Ao se levar em consideração a assertiva de que a cultura nada mais é do que o conjunto de narrativas que contamos a nós mesmos sobre nós mesmos, e sobre os outros, deduz-se que narrar a si mesmo equivale não apenas a um questionamento individual sobre os saberes e a cultura, mas à produção de novas modalidades de saber.

Ao contrário dos romances de Puig e de Abreu, que abor-

5 Sexualidad y revolución, livro citado por Puig nas notas de rodapé de El beso de la mujer araña, é uma invenção ficcional interna à diegese do romance, tal como o próprio Puig afirma em entrevista a José Amícola e Manfred Engelbert. Esta entrevista foi incluída como apêndice em AMÍCOLA, 1992, p. 270-296. dam o tema da intervenção social através da escrita dentro de suas narrativas, em No se lo digas a nadie é um elemento paratextual que anuncia o papel subversivo da escritura. Antes mesmo de dar início à atividade de narrativização da trajetória de Joaquín Camino, há uma advertência no livro, que permite identificar a projeção do autor como significante no romance: "las historias que aquí se narran solo ocurrieron en la imaginación del autor; qualquier semejanza con la realidad es pura coincidencia" (BAYLY, 1994, p. 4). É Mikhail Bakhtin, contudo, que nos alerta para o fato de que, por trás das palavras do narrador, aloja-se o 
juízo de valor do próprio autor, de maneira que tal advertência, ao invés de dissipar o conteúdo ideológico do discurso do narrador, o evidencia: "o autor se realiza e realiza o seu ponto de vista não só no narrador, no seu discurso e na sua linguagem [...] mas também no objeto da narração, e realiza também o ponto de vista do narrador. Por trás do relato do narrador nós lemos um segundo, $O$ relato do autor sobre o que narra o narrador" (BAKHTIN, 1998, p. 118). Se o autor de No se lo digas a nadie afasta-se, em sua advertência ao leitor, do narrador que criou para conduzir sua narrativa, é justamente porque a este narrador é atribuída autoridade para apresentar o enredo como textualização da sociedade, através da legitimidade da instituição literária. É porque prevê o impacto de sua escrita no meio social que o autor salienta seu distanciamento com relação ao narrador engendrado na escrita literária. Tal narrador, por sua vez, manifesta um desacordo tácito com as ideologias nacionalistas (as quais subscrevem as hierarquias de gênero, a premissa heteronormativa, a manutenção do modelo hegemônico de masculinidade, o racismo e o preconceito de classe) do universo que narra. É na contra-identificação do narrador com Luis Felipe e Maricucha, em oposição à identificação solidária com o personagem Joaquín, que se dá a perceber a intervenção cultural operada pelo narrador.

Como função textual e pluridiscursiva, o ideologema do corpo refrata os discursos médico, jurídico e psiquiátrico sobre os limites do corpo biológico, bem como a sua inscrição na cultura como significante social. Para Manuel Puig, importa problematizar o regime binário dos corpos sexuados, os quais são tomados como determinantes na constituição do gênero. A subversão do ideologema do corpo em Puig se dá, contudo, na composição de um personagem, Molina, o qual transita entre o gênero masculino e o gênero feminino, a despeito da materialidade do seu corpo biológico masculino. $\mathrm{O}$ investimento no corpo como signo de resistência política também é operacionalizado na construção do personagem Valentín, o qual, mesmo estando mergulhado profundamente nos pressupostos de uma masculinidade heterossexual, tem uma aguda percepção do corpo como um lugar de resistência política, uma vez que é através da tortura do corpo que o aparato estatal repressivo tenta disciplinar o guerrilheiro. Puig, Abreu e Bayly sugerem, por meio das vozes narrativas que constituem seus romances, que as imposturas com relação à performatividade do gênero embaçam a legibilidade cultural de certos corpos: os corpos não-heterossexuais.

O efeminamento de Molina e a sua orientação sexual colaboram para que Valentín não reconheça a imaginação de Molina como um procedimento cognoscente válido para compreender a tortura, ao mesmo tempo em que Valentín considera a sua própria imaginação como recurso dotado de validade epistemológica para conhecer a verdade sexual do corpo de seu 
companheiro de cela. Comportamento análogo ao de Valentín é descrito pelo narrador de Onde andará Dulce Veiga?, com relação ao personagem Jacyr(a), na primeira metade do romance. Mesmo que o narrador não compactue com o juízo de valor que apresenta - o que pode ser indiciado na ironia utilizada pelo mesmo - ele denuncia, através dos olhares de soslaio das velhinhas de preto que residem no edifício, a repulsa silenciosa delas com relação ao filho travesti de Jandira de Xangô. "Desviar-se" da identidade de gênero auspiciada pelo seu sexo biológico condena Jacyr(a) a uma condição de degeneração, de marginalidade e de abjeção (no sentido que Judith Butler dá à expressão), o que equivale, em última análise, a condenar o mulato travesti a uma condição de "sujeito de segunda categoria", quando não de "não-sujeito", isto é, de sujeito-abjeto.

Para Caio Fernando Abreu, o corpo é visto como a matéria-prima que, através de uma "ascese do eu" (ou ainda, de uma tecnologia de subjetivação), servirá como instrumento para se escapar às teias da heteronormatividade. Tal estratégia está representada na proliferação das possibilidades eróticas por parte do protagonista, incluindo-se aí a masturbação, o intercurso sexual com homens e algumas "aventuras" com mulheres. Estes usos do corpo não visam exclusivamente a um gozo de ordem libidinal, visto que também configuram práticas de subjetivação a contrapelo dos discursos heteronormativos. O personagem Jacyr(a) ora se apresenta como homem, ora como Jacyra, assinalando também um reflexo contestatório, na medida em que suas performances de gênero desestabilizam o continuum "sexo - gênero - desejo (heterossexual)" pressuposto pelos discursos hegemônicos que postulam uma identidade de gênero "coerente". Declinando-se ora no feminino, ora no masculino, Jacyr(a) pleiteia o direito à autodeterminação de identidade de gênero, colocando em xeque o caráter de transtorno psicológico utilizado pelo discurso psiquiátrico para caracterizar a disforia de gênero. ${ }^{6}$

Finalmente, Jaime Bayly, ao construir o personagem Joaquín, explicita o fato de que, em sociedades masculinistas como a peruana, não é sequer necessário transpor a barreira entre o masculino e o feminino para que o sujeito sofra retaliação. Em No se lo digas a nadie, pequenos indícios de subversão ao modelo hegemônico de masculinidade acionam os dispositivos ideoló-

6 A disforia de gênero (também chamada de "transtorno da identidade de gênero") é caracterizada pelo DSM IV (Diagnostic and Statistical Manual of Mental Disorders, publicado pela American Psychiatric Association) como um dos transtornos mentais envolvendo identidade e comportamento sexuais. gicos que se materializam no discurso disciplinador da escola e no discurso classificatório da Igreja Católica (o qual sequer pode ser chamado de "salvacionista", uma vez que a divisão entre "virtuosos" vs. "pecaminosos" premia os primeiros, condenando os segundos ao inferno). A abjeção com relação aos que não desempenham corretamente suas identidades de gênero, tais como as travestis que vivem do trottoir, é apresentada pelo narrador de maneira mais explícita do que nos romances de Abreu ou Puig. No romance de Bayly, a heteronormatividade 
é denunciada através da faceta cruel do discurso homofóbico, que não raro "materializa" seus efeitos através da humilhação verbal, da retaliação e da violência física. É denunciada assim a condição abjeta daqueles corpos que não cumprem de maneira adequada os seus papéis de gênero. A violência homofóbica está representada na obra de Jaime Bayly quando Gustavo, Juan Ignácio e Joaquín, em pleno frenesi causado pelo consumo de cocaína, saem pela noite a espancar travestis. O exercício da sexualidade, acoplado a uma performance disjuntiva de gênero, transforma o corpo das travestis em abjeções ininteligíveis para a "mentalidade hetero". Destarte, são os corpos das travestis que demarcam, para os personagens Gustavo e Juan Ignácio, os limites da legibilidade cultural das performances de gênero. Se é verdade que, em No se lo digas a nadie, deflagra-se certa tolerância com relação às práticas homossexuais veladas, tais como as de Alfonso ou Gonzalo, também é verdade que elas são aceitas na exata medida em que compactuam com o status quo, ao não deslocar o limite imposto pelas pressuposições relativas à identidade de gênero masculina. As travestis, por sua vez, são consideradas como a escória dentre todos os outsiders sexuais: tal juízo está tão arraigado no pensamento de Gustavo e Juan Ignácio que ambos chegam a associar a idéia de extermínio das travestis a uma prática supostamente ufanista, ao declararem "matemos un cabro, hagamos pátria" (BAYLY, 2003, p. 230).

De acordo com Teresa de Lauretis, "the relation of narrative and desire must be sougth within the specificity of a textual practise, where it is materially inscribed" (DE LAURETIS, 1984, p. 106). Pensar o desejo implicado na estrutura narrativa requer, por extensão, considerar que "the very work of narrativity is the engagement of the subject in certain positionalities of meaning and desire" (DE LAURETIS, 1984, p. 106). É nesse sentido que se compreende o ideologema do desejo: a articulação de uma narrativa sempre se dá a partir de uma posicionalidade do sujeito, a qual envolve o desejo e a produção de significados. Assim, a função intertextual identificada no corpus sob a égide do desejo é a de que, ao se representar, no texto literário, um significado para a especificidade de se viver socialmente uma identidade sexual subalternizada, tal especificidade é articulada a partir de um desejo por reconhecimento. Puig, ao deslocar o narrador para as notas de rodapé, coloca os significados instituídos pelo discurso ficcional em paridade com o discurso científico sobre a homossexualidade, como estratégia para legitimar a enunciação de seu narrador (que subscreve a idéia de que a homossexualidade pode configurar um posicionamento revolucionário). Ao mascarar o locus do narrador através da criação de uma "personagem" sexóloga, o narrador de Puig reivindica um terceiro espaço de produção de saber, no qual seja possível a síntese entre a revolução política e a revolução sexual. 
No romance de Caio Fernando Abreu, a narrativização das experiências vividas por um narrador interno a posteriori desvela um investimento político diferenciado na busca pela autoridade narrativa. Ao invés de deslocar o narrador para uma dobra textual, como Puig, Abreu lança mão da experiência vivida pelo narrador-protagonista para legitimar os significados que este produz ao narrar sua própria história. Tal hipótese pode ser comprovada a partir de uma fala da personagem Dulce Veiga, depois que o jornalista a encontra, em Estrela do Norte: “diga o que você quiser, faça o que você quiser. Não diga nada, se achar melhor. Minta, não será pecado. Mas se contar tudo, não esqueça de dizer que sou feliz aqui. Longe de tudo, perto do meu canto" (ABREU, 1990, p. 212 - grifo meu). O narrador de Abreu, efetivamente, conta tudo, mas por quê? Mais do que o desejo de narrar a descoberta do paradeiro de Dulce Veiga, a cantora desaparecida, é o desejo de contar a sua própria história, e de ter sua identidade (ainda que precária e provisória) reconhecida através de sua narrativa, que o mobiliza em seu papel de narrador. Está implícito, neste gesto, o desejo do narrador de ser reconhecido em suas especificidades que o constituem como sujeito histórico por aqueles que lerão a sua história.

Jaime Bayly, por sua vez, recorre a um narrador externo, supostamente neutro com relação aos fatos narrados, na tentativa de evocar o distanciamento entre autor e narrador, bem como entre narrador e personagens, para asseverar os juízos implícitos na voz narrativa. Todavia, como foi possível depreender da análise da conjunção de um narrador externo com um focalizador interno (ao final do romance), desvela-se o fato de que o narrador subscreve o ponto de vista do protagonista. Uma vez mais, o desejo por reconhecimento se mostra constitutivo da narratividade do texto, dado que o narrador se pretende livre de comprometimentos para que seu dizer seja reconhecido como uma verdade que aspira à legibilidade social.

Através de seus romances, Manuel Puig, Caio Fernando Abreu e Jaime Bayly projetam uma mesma intencionalidade: a de engendrar significados sociais que textualizem as práticas homossexuais entre homens, deslocando e relativizando os preceitos identitários ditados pela matriz heteronormativa. Destarte, o texto ficcional se faz uma ficção política, na medida em que aciona o desejo de intervenção na cultura a partir da práxis cultural. Em última análise, a leitura comparativa destes três romances evidencia que, tomando por base uma análise dos procedimentos narrativos, é possível apreender as apostas políticas subjacentes em um texto literário. Tal como salienta Bakhtin, "o sujeito que fala no romance [o narrador] é sempre, em certo grau, um ideólogo, e suas palavras são sempre um ideologema. Uma linguagem particular sobre o mundo representa 
sempre um ponto de vista particular sobre o mundo, que aspira a um significado social" (BAKHTIN, 1998, p. 135).

Cabe ainda perguntar, contudo, se o investimento político em representações sociais subversivas (as quais desnudam as opressões sofridas pelos outsiders sexuais latino-americanos, bem como as ambivalências com as quais tais sujeitos se deparam) poderia funcionar como mecanismo de intervenção cultural. Conseguiria a literatura redimensionar as estruturas de pensamento mobilizadas para a interpretação desses sujeitos sociais na literatura representados? Fredric Jameson pergunta-se: "o texto é um objeto autônomo ou 'reflete' um contexto ou campo $\mathrm{e}$, neste segundo caso, apenas repete ideologicamente esse contexto ou campo, ou possui um acerta força autônoma graças à qual poderia ser visto como uma negação desse contexto?" (JAMESON, 1992, p. 34).

Uma vez que os artefatos culturais são aqui compreendidos, tal como sugere Jameson, como atos socialmente simbólicos, e que a literatura pode ser vista como um artefato cultural de caráter performativo, é legítimo e procedente afirmar que as representações subversivas da sexualidade na literatura não funcionam apenas como a negação de um contexto social heteronormativo. Mais do que simplesmente negar esse contexto, elas assumem o caráter de intervenção, já que narrativizam o mundo, as vivências e as maneiras pelas quais os indivíduos se organizam coletivamente, construindo novos sentidos para as práticas sexuais socialmente relegadas ao plano da abjeção. Ao narrar as trajetórias de personagens como Molina, que reivindica a autodeterminação de gênero, como Joaquín, que luta pelo reconhecimento de sua sexualidade no seio da família e da comunidade nacional a qual pertence, ou como o jornalista anônimo que refuta as identidades homossexuais pré-determinadas, estes narradores criam um capital cultural subversivo, o qual erode a legitimidade monolítica das identidades sexuais, abrindo novas possibilidades de auto-reconhecimento para os sujeitos sociais através da literatura. É em torno deste projeto que é estético, mas também ético, que os ideologemas da letra, do corpo e do desejo se superpõem, fazendo do texto literário uma tecnologia de subjetivação na qual, através da leitura, sujeitos outrora ininteligíveis reconheçam a si mesmos como sujeitos plenos, reescrevendo-se de maneira reiterada no campo das representações culturais a partir da politização dos usos do corpo, do cultivo dos prazeres e da busca por afeto.

\footnotetext{
Abstract:

This paper aims at analyzing in a contrastive way three representative novels of the problematic of
} 
the male homosexual identity in Latin America: Manuel Puig's El beso de la mujer araña (Argentine, 1976), Caio Fernando Abreu's Onde andará Dulce Veiga? (Brazil, 1990) and Jaime Bayly's No se lo digas a nadie (Peru, 1994). The articulation of a queer epistemology allows us to think about textuality as a place of dramatization of a politic fiction that questions the heteronormative patterns of sex and gender, and proposes a strategy of resistance based both on bodies and pleasures and on politics of representation and reinvention of masculinities and femininities. Taking feminist assumptions, narratology and queer theory/epistemology as theoretical basis, it is made a critical reading of these novels, which are presented against the heteronormative model and invest in the subversive potential of a place of enunciation in the literary discourse marked by difference and resistance to the heteronormative disposals of regulation of sexual identities. At last, the contradictions and impasses that emerge from the novels are analyzed, particularly in which concerns questions of race, class and gender, as well as the potentialities and problematic points of a queer poetics as a place of cultural intervention.

Keywords: Narratology. Latin American Literature.Queer poetics.

\section{Referências}

ABREU, C. F. Onde andará Dulce Veiga? São Paulo: Companhia das Letras, 1990.

ACHUGAR, Hugo. Planetas sem Boca. Belo Horizonte: UFMG, 2006.

ALÓS, Anselmo Peres. Madame Satã e a Encenação do Feminino: Impasses de um Malandro Travestido de Vermelho. In: Revista Gênero (UFF), Vol. 8, Niterói, 2008. p. 369-385.

. Heterotopias do Desssossego: Literatura e Subversão Sexual na América Latina. In: Revista Cerrados (UnB). Vol. 27, ano 18, Brasília, 2009. p. 231-249.

ANDERSON, Benedict. Nação e Consciência Nacional. São Paulo: Ática, 1989.

AMERICAN PSYCHIATRIC ASSOCIATION. DSM IV. 4 ed. Porto Alegre: ArtMed, 2002.

AMíCOLA, José. Manuel Puig y la tela que atrapa al lector. Buenos Aires: Grupo Editorial Latinoamericano, 1992. 
BAKHTIN, Mikhail. Questões de Literatura e de Estética: A Teoria do Romance. Trad. Aurora Fornoni Bernardini et alli. São Paulo: UNESP; HUCITEC, 1998.

BAYLY, Jaime. No se lo digas a nadie. Barcelona: Seix Barral, 1994. BHABHA, Homi K. O Local da Cultura. Belo Horizonte: UFMG, 1998.

BUTLER, Judith. Bodies That Matter. In: Bodies That Matter. London: Routledge, 1993. p. 27-56.

. Revisiting Bodies and Pleasures. Theory, Culture E Society. SAGE: London, Thousand Oaks and New Dheli, 1999. v. 16, n. 2, p. 11-20.

. Problemas de Gênero. Trad. Renato Aguiar. Rio de Janeiro: Civilização Brasileira, 2003.

DE LAURETIS, Teresa. Alice Doesn't: Feminism, Semiotics, Cinema. Bloomington and Indiana: Indiana University Press, 1984.

EAGLETON, Terry. Marxismo e Crítica Literária. Trad. Antonio Sousa Ribeiro. Porto: Afrontamento, 1978.

Teoria da Literatura: Uma Introdução. Trad. Waltensir Dutra. São Paulo: Martins Fontes, 1983.

JAMESON, Fredric. A Interpretação: A Literatura como Ato Socialmente Simbólico. In: O Inconsciente Politico. Trad. Valter Lellis Siqueira. São Paulo: Ática, 1992. p. 15-103.

JORNAL do Nuances. Ano 1, v. 1. Porto Alegre, janeiro de 1998. p. 8.

MCGEE, Patrik. Telling the Other: The Question of Value in Modern and Post-Colonial Writing. Ithaca: Cornell University Press, 1992. PROBLEMAS FEMININOS (Female Trouble). Direção e roteiro: John Waters. Estados Unidos, 1974, 35 mm. 97 min.

PUIG, Manuel. El beso de la mujer araña. Buenos Aires: Seix Barral, 1976.

SAID, Edward W. Cultura e Imperialismo. Trad. Denise Bottman. São Paulo: Companhia das Letras, 1995.

SEDGWICK, E. K. The Epistemology of The Closet. Berkeley: The University of California Press, 1990.

WITTIG, Monique. The Straight Mind and Other Essays. Boston: Beacon Press, 2002. 